\title{
Quem tem medo do saber não sabido? Determinantes da relação com o saber na formação de professores-estagiários
}

\section{Who is afraid of the unknown knowledge? Determinants of the relation with knowledge in the formation of teachers-trainees}

\author{
Jean-Marie Weber ${ }^{1}$ \\ Julia Strohmer ${ }^{2}$
}

\begin{abstract}
RESUMO
O objetivo de todo professor é o de transmitir saber, bem como de apoiar e acompanhar os jovens em seu desejo de saber. Assumir a função de professor requer questionar-se sobre a relação com o saber, tanto do aluno quanto o seu próprio. Os futuros professores devem, portanto, enfrentar a pergunta se eles querem ou não assumir essas funções. Por meio de uma pesquisa qualitativa longitudinal, os autores desse artigo interessaram-se pelos processos de subjetivação e de profissionalização de futuros professores, e isso a partir de uma perspectiva psicanalítica de orientação lacaniana. Auxiliados por estudos de casos individuais e pela elaboração de uma tipologia, esse projeto de pesquisa visa à correta determinação e a conceitualização de percursos de formação com desenvolvimentos bem-sucedidos, abortados ou problemáticos.
\end{abstract}

Palavras-chave: ensino; relação com o conhecimento; psicanálise; profissionalização.

DOI: $10.1590 / 0104-4060.49812$

1 Universidade de Luxemburgo. Faculdade de Letras, Ciências Humanas, Artes e da Ciência da Educação. Maison des Sciences Humaines. 11, Porte des Sciences L-4366 Esch-sur-Alzette. E-mail: jean-marie.weber@uni.lu

2 Instituto de Pesquisa na Universidade de Luxemburgo. 2, Avenue de l'Université. L-4365 Esch-sur-Alzette.E-mail: julia.strohmer@erziehungsfragen.lu 


\begin{abstract}
The professional objective of any teacher is to impart knowledge, but also to foster and satisfy the desire for knowledge in young individuals. It is thereby also part of the function of a teacher to take an interest in the relation to knowledge, both that of students and their own. Prospective teachers thus have to deal with the question of whether or not wanting to assume this task. By means of a longitudinal qualitative study, the authors of this project engage with the topic of subjectivation and professionalization of prospective teachers, from an explicitly psychoanalytic Lacanian perspective. By way of individual case studies and the elaboration of a typology, this research project aims to ascertain a way of reflecting in a theoretically well-founded manner on successful, abortive, problematic or imperilled developments during the training process.
\end{abstract}

Keywords: teaching; relation to knowledge; psychoanalysis; professionalization.

Como se encontra a relação singular de professores estagiários com o saber? Como esse se desenvolveu? E de que modo se articulam a relação com o saber respectivamente aos processos de formação e de profissionalização? Eis algumas questões que nos preocupam em nossas pesquisas. O projeto de pesquisa intitulado Clinical analysis of secondary school student teachers' personal relation to knowledge in connection with their construction of a professional identity ${ }^{3}$ (CATKRI) está baseado em quatro entrevistas realizadas com dez alunos de Luxemburgo e de Lausanne, durante seu percurso de formação pedagógica. Por meio de seus discursos e palavras gostaríamos de compreender melhor os professores-estagiários enquanto sujeitos em seu desejo e resistência em aprender, ao saber e à transmissão do saber. Em seguida ao desenvolvimento de nosso enquadre de referência teórica, apresentaremos os discursos dos protagonistas para analisar sua relação com o saber. Trata-se de observar se essa relação produziu disfunções, sintomas, e se ocorreu, ao longo da formação, uma transformação de sua relação com o saber e, portanto, do trabalho com o sintoma. Finalmente, faremos uma associação desses aspectos à possível questão da articulação entre a relação com o saber próprio do ensino e aquele que é transmitido a seus alunos.

O termo relação com o saber foi formulado inicialmente por Lacan (1966, p. 793), e foi pertinentemente utilizado e desenvolvido no campo das ciências da educação. Charlot (1997) e a equipe ESCOL (Education, Socialisation et

3 Análise clínica da relação pessoal com o conhecimento de professores de alunos de escola secundária relacionada à construção de sua identidade profissional. 
Collectivités Locales) trabalharam esse conceito, entre outros, para analisar o fracasso escolar. Como ele, Rochex (2004) interessou-se pela questão do sentido dado ao saber e na Escola por seus alunos. Chevallard (1992) acentuou o aspecto institucional da relação com o saber. Brousseau (1986) e Hatchuel (2005), bem como Terrisse (2007) desenvolveram o conceito para sua abordagem clínica com orientação psicanalítica no campo educativo.

\section{Problemática e enquadre teórico}

\section{A relação com o saber: uma dimensão da singularidade do sujeito}

O saber designa primeiramente um objeto, isto é, o conjunto infinito dos diferentes conhecimentos. Mas ele constitui igualmente um ato, enfim, como saber não sabido ou saber inconsciente, uma instância do sujeito. (MENÈS, 2012). Para além dos diferentes saberes, existe a relação afetiva com esse saber. Com efeito, pode-se aprender muito sobre o funcionamento das estrelas, de um computador ou de um texto, mas nada se sabe sobre o motivo que nos leva a essa aprendizagem. A expressão "relação com o saber" designa, segundo Martine Menès (2012, p. 22), o conjunto das relações afetivas, cognitivas, psíquicas e práticas que o sujeito, confrontado à necessidade de aprender, mantém com os objetos de conhecimento do mundo que o cerca. Efetivamente, a partir do momento em que o ser humano pergunta por que ele é atraído por um ou outro saber, ele se interessa por ele mesmo enquanto indivíduo e sujeito. Ele quer se conhecer enquanto eu (registro do imaginário), mas ele também quer desenvolver um saber relativo à sua relação com o saber (registro do simbólico): ele questiona seu desejo e sua angústia de saber, seu ser de desejo. Nessa iniciativa, ele pode finalmente chegar à pergunta do que faz furo no saber, sobre os limites de seu saber sobre si mesmo e o mundo (registro do real).

Para Freud, esse desejo de saber nasceu no momento em que a criança começa a se perguntar sobre as realidades que lhe são difíceis de apreender pelo pensamento, tais como a morte, o nascimento, a sexualidade ou o amor, bem como o desejo do outro. (FREUD, 1908; 1905).

O saber, sob suas diferentes figurações, apresenta-se sob formas de significantes e de objetos libidinais buscados pelo desejo de qualquer aprendiz. Nossa relação com o saber é assim uma questão de desejo, de gozo e, portanto, de afetividade. Desse modo, ele é dito pulsional. Com efeito, ele se caracteriza pelas pulsões escópica, oral e anal. (MENÈS, 2012, p. 57-64). Aprender cons- 
titui um ato de gozo, mas implica igualmente em uma perda de gozo graças ao recalque ou à sublimação.

O desejo de saber se descobre essencialmente na relação com o outro, na transferência que, para Lacan (1973, p. 210) se desenvolve porque o sujeito supõe saber a algum outro. "A transferência é amor dirigido ao saber" (LACAN, 2001, p. 95) e, assim, do mesmo modo, amor por quem tem o saber. Mas, em alguns momentos, não queremos chegar ao saber. Nós o evitamos por angústia da falta, do real, por exemplo, do pulsional que nos constitui. Assim nos situamos mais no "horror do saber", pois o saber é sempre saber de uma falta. (LACAN, 2001, p. 309). Preferimos então o desconhecimento inconsciente [...] ou a ignorância, o que, segundo Lacan, constitui uma das maiores paixões. (LACAN, 1966, p. 358). Vê-se bem que a relação com o saber é singular e assim potencialmente de forma sintomática. Ao evocar esses aspectos da relação com o saber, nada surpreende, enquanto que no que se refere ao sujeito humano, Lacan (1966, p. 793) fala de "uma mediação facilitada para situar o sujeito: uma relação com o saber".

O professor tem a tarefa de transmitir saber, auxiliar os jovens a aprender e a construir saber para poder colocar o mundo em signo, para pensar sobre sua relação com o saber e para se posicionar até mesmo em relação à sua paixão por ignorância. A partir de então podemos supor que a questão da relação singular com o saber do estagiário deve ser trabalhada no enquadre de uma formação profissionalizante. Coloca-se a questão de saber de que modo o futuro professor pode se formar ocupando, face a seus alunos, o lugar de suposto "sabente" ou na transferência de suposto saber (LACAN, 1973, p. 228) e de que modo as disfunções a esse respeito podem ser analisadas em uma abordagem clínica de orientação psicanalítica.

\section{Posicionamento epistemológico}

Optamos por uma abordagem clínica porque é pela singularidade e pela subjetividade individual que podemos dar conta de um modo melhor da "parte enigmática do encontro humano". (BLONDEAU, 2006, p. 32). Nossa abordagem visa separar a lógica de uma história de vida singular em luta com as situações complexas em que a relação com o saber está em jogo.

Partimos de entrevistas, e, portanto, com a fala e com a interpretação de sua vivência para o estagiário. A exemplo de Freud (1937a, p. 47-48), tentamos construir a lógica específica, uma coerência e uma evolução nas propostas. $\mathrm{O}$ estudo de caso tal como o concebemos realiza-se sempre em relação aos dois polos da linguagem e do real, portanto, igualmente do que faz furo no saber do protagonista. Uma pesquisa que visa o singular constitui uma iniciativa que se interessa pela "bordagem" das palavras sobre o furo do que pode se dizer, índice do real. (SAURET; DOUVILLE, 2006, p. 15). 
Partir de estudos de casos é finalmente questionar-se sobre a verdade. Experimentamos conosco mesmo que "a dúvida é realmente o método de pesquisa, a guardiã da honestidade, da abertura, da confiabilidade de uma iniciativa, que sem ela corra o risco de ser um castelo de cartas".

\section{Processo metodológico}

A coleta dos dados foi realizada por entrevistas de tipo qualitativo-episódico. (FLICK, 2011). Sete estagiários de Luxemburgo e três suíços de Lausanne foram entrevistados quatro vezes ao longo de seu percurso de formação.

Durante nossas leituras, ficamos atentos a palavras/significantes que nos falam por sua equivocidade, nos surpreendem pelo vínculo no mínimo com um outro, acabam por formar cadeias de significantes e com efeito de significação sobre um eixo, seja ele metonímico, seja metafórico. (RAVAZET, 2002, p. 84-90). Com Lacan, consideramos os significantes e suas articulações como o instrumento e como o depósito do conhecimento dos novatos. Conforme seu posicionamento em uma banda de Moebius, eles podem estar conscientes ou recalcados em diferentes momentos. (CHAUMON, 2004, p. 15). Eis porque é igualmente a relação do sujeito com seu enunciado que nos importa.

Tentamos detectar significantes-mestres dos protagonistas. Seguindo Lacan, consideramos que "um significante-mestre (notado S1) é um significante que polariza um saber do exterior, ordena o modo como é apresentado em um discurso, preside à sua lógica interna e dita seus lugares aos significantes que ele reúne”. (SAURET, 2005, p. 10).

Sempre com base nos significantes em jogo, no sujeito dividido entre significantes, questionamo-nos sobre o posicionamento inconsciente dos sujeitos em relação ao desejo e ao gozo. Entre outros, vemos aí que significado eles atribuem a que saber. Feito esse trabalho, questionamos os discursos orais para ver se há transformações no nível da relação com o saber. Analisamos tanto as razões quanto os processos que conduziram a essas mudanças e isto em uma perspectiva psicanalítica do sujeito dividido entre desejo de saber e de gozo do não saber.

\section{Construção, disfunções e evolução da relação com o saber}

Continuando, iremos apresentar a história e as lógicas típicas que pudemos detectar em relação ao saber em evolução. Por razões de espaço, iremos nos limitar a cinco casos representativos. 


\title{
Hélène $^{4}$
}

É uma professora de francês que vem de um meio "proletário" e que se diz ser "uma grande inquieta". Sobre o discurso "muito responsabilizador" de seus pais, ela se lembra da injunção "queremos que vocês estudem na classe". Ela se identificava com isso. Para preparar suas aulas, ela investe um tempo enorme e até sacrifica o lado relacional.

Ela diz ser curiosa, evocando o aspecto prazenteiro da relação com o saber, sob risco de culpar-se por isso: "Sim, eu diria que desde minha infância sim, totalmente sim. Porque sempre fui muito curiosa, ou seja, muito curiosa em relação às pessoas, então às vezes isso pode ser um pouco mal interpretado, mas também... sim, sim, sim... Digamos que eu pudesse passar horas, horas no meio da sala com dicionários." Sobre esse ofício de professora ela segue a via de sua mãe, que teve que deixar rapidamente esse ofício por questões de doença.

São significantes-mestres que se repetem em um discurso e mostram assim sua importância para o indivíduo em questão. Assim, essa estagiária diz:

\begin{abstract}
Mas ai é verdade que eu me dou conta de que tenho mais esse lado, por exemplo, explicação, vamos dizer o francês, estruturação, porque com meu olhar posso explicar os fenômenos, o porquê, etc., porque e como, enquanto que na literatura, de certo modo, eu me re... sinto-me um pouco insegura. Então pode ser que seja eu mesma que tenho essas percepções, aparentemente, enfim, pode não ser necessariamente o caso, mas sinto-me insegura, na verdade não tenho certeza do que digo. E tenho às vezes uma tendência a buscar a aprovação, enquanto que na gramática posso explicar porque o particípio passado é assim, é assado, posso até mesmo (indicar) porque o particípio passado deve concordar...
\end{abstract}

Para essa estagiária são importantes os aspectos da estruturação e da busca de uma certa segurança, e que também influenciaram a escolha da disciplina estudada: a linguística. Por outro lado, isso permite a ela não ter que buscar a aprovação do Outro, atitude que a desagrada.

Durante seus estágios, ela se vê diante do enigmático e da dúvida. Ela descobre o real em seu aspecto pulsional na classe: o que justamente não se pode dominar. Ela diz, por exemplo: "Quero que as aulas comecem na sétima porque podemos fazer um trabalho real porque depois, quando eles chegam à oitava [...] é extremamente dificil, são os hormônios".

4 Os nomes próprios foram mudados para manter esse corpus anônimo. 
E ela continua:

sim, sim, disse a mim mesma que não sou feita para isso. Sim, foi o que me disse. Finalmente, eu até, estava tão desmoralizada uma vez que chamei o médico de plantão, era noite e eu me disse não, não aguento mais, não é mais possivel, [...] eles me encaminharam para, para um psiquiatra. No dia seguinte eles me disseram para ir à emergência psiquiátrica, portanto, para uma consulta psiquiátrica e depois disso eu melhorei.

Com efeito, ela se fechou em um jogo imaginário de poder com seus alunos: "não posso deixar passar nada. ... Eu os puni diretamente". Ela só compreendia as contestações dos alunos como "para me testar". O que a auxilia a sair do problema é dar-se conta de que não há "autoridade natural", (mas que) " $a$ autoridade se adquire". Esse discurso diferente é "desculpabilizante" e permitia que ela usasse uma outra estratégia. Um formador aconselhou-a a acalmar-se, a não insistir em colocar uma observação diretamente sobre a agenda de um aluno, mas esperar, deixar um espaço de tempo, para que o aluno também possa se acalmar. Ela tinha medo de colocar em prática essa estratégia, de passar para uma outra lógica: "Eu tinha medo de esquecer de pedir". Então ela teme a falta, ela teme fazer furo.

Houve, portanto, a repetição de uma conduta sintomática, o que segundo Freud e Lacan é característico da pulsão de morte. (LACAN, 1986, p. 251). Suas repetições levam-na a um ponto em que ela não aguenta mais. Finalmente, ela aceita o discurso de seu formador e desenvolve uma relação menos obsessiva com a transmissão do saber.

Em torno do fim de seu percurso, ela sabe lidar melhor com o impossível da profissão de professor e da transmissão do saber como o expressa a metáfora do semeador de pequenos grãos: "É bom estar na sala com os alunos, e também o contato com eles ... é bom ensinar-lhes algo. Eu me digo pronto, planto sementinhas. Então, como elas - não sei, mas é isso, pronto, planto grãozinhos. É isso sim".

Ela sabe abrir "paren-theses", distanciar-se do discurso de seus pais e permitir o diálogo, que constitui sempre um risco: "Não, não é fácil é sempre a ocasião que faz o ladrão. De repente... estudamos algo, podemos fazer um parêntese porque um aluno fez uma pergunta sobre um ou outro assunto ah sim, isso pode introduzir algo que permita finalmente ir além do que eles podem pensar inicialmente..."

5 Em francês parents significa pais. 
Agora Hélène tem palavras para falar de seu lugar, ideais e uma estratégia para lidar com sua relação perfeccionista com o saber, isto é, seu compromisso fantasmático no ofício de professor, dependendo do discurso do Outro e da relação com as imagos parentais. Ela pode se dar conta de que a transmissão é impossível sem dar direito ao desejo de saber do outro. O aluno em demanda ocupa agora um lugar de sujeito. Eis um início de transformação que ocorreu para ultrapassar seu medo da insegurança. Essa metáfora de "plantar grãozinhos" é assim uma parada certamente benéfica.

No início de sua formação, a relação com o saber parece se situar entre curiosidade e busca de estruturação. A falta de domínio a preocupa. Parece-nos que sua relação com a transmissão do saber mudou no fim. Como Freud (1937b, p. 94), ela afirma de seu modo: "podemos estar imediatamente seguros de um sucesso insuficiente". Para alguns, é, portanto, o contato com o impossível do ofício (FREUD, 1937b, p. 94) que os leva adiante. Ela sabe aceitar uma certa diferença, a falta, o impossível, e passar de uma relação baseada no imaginário a um laço ancorado no simbólico. Ela parece estar pronta a assumir-se como sujeito dividido no domínio profissional.

Como Hélène, há professores-estagiários que em um primeiro tempo transmitem sua própria relação com o saber e que, graças a disfunções, são chamados a realizar transformações. Graças a novos significantes ou a significantes articulados de um novo modo, eles começam um trabalho que acaba por transformar sua relação com o saber a transmitir.

\section{Martin}

Martin é professor de educação física e esportiva. Após ter feito uma formação em enfermagem, ele decide prosseguir seus estudos em ciências do esporte com o objetivo de se tornar professor.

Em seu relato, o significante "movimento" é central. É um significante mestre que o leva igualmente a estudar as ciências do esporte. Tendo feito enfermagem, ele afirma no après-coup: "Para mim, o que falhou foi o fato de só ter contato com pessoas doentes ou com pessoas que eu acompanhava eventualmente até que eles recuperassem a saúde. Mas, a meu gosto, não havia esporte suficiente em tudo isso. Quero dizer que eu manejava seringas, curativos, etc. E acho que faltava movimento...".

Sobre sua relação com o saber não surpreende que essa seja caracterizada pela ideia do desenvolvimento, termo que substitui o do movimento: 
O que não significa que não estejamos abertos a novos desenvolvimentos, não é? É preciso conferir regularmente que... Não gosto de ficar parado, sempre gosto de ver o que há de novo e se posso usar isso. Só que, durante o estágio, preciso de uma certa base para que eu possa fazê-lo durante o periodo probatório. E isto continua depois, não?

Estamos então em uma cadeia significante ao longo da qual desliza seu desejo. Mas há um ponto de "capiton" que faz parada e que é importante para ele. Ele precisa de uma base de conhecimento, bem como uma ancoragem institucional, e, portanto, um emprego.

$\mathrm{Na}$ lógica de seu discurso, a falta e o furo no saber têm seu lugar para continuar a se desenvolver: "Não gosto de parar, gosto de ver o que há de novo". É assim que ele faz outros cursos fora de sua formação para um aperfeiçoamento em diferentes aspectos de sua disciplina.

$\mathrm{O}$ que ele quer transmitir é o gosto pelo movimento. Esta é a base e a finalidade de seu ensino:

Em primeiro lugar, falo do prazer, do gosto pelo movimento, isto é, não fazer esporte simplesmente para fazer parte, para participar, ou porque se tem prazer ou porque... Enfim, cada um tem seus próprios pontos de atividade, suas próprias razões, mas penso que no domínio do esporte é importante que haja prazer, que eles aprendam algo de novo, que progridam, que participem das aulas com comprometimento e finalmente, sim, que eles tenham prazer com o esporte. Certamente, nem todos os alunos partilham esse gosto pelo esporte, e tenho plena consciência disso, mas seria preciso que a maioria tivesse prazer.

Ele desenvolve bem um estilo em que fica atento à capacidade corporal e esportiva que falta aos jovens. Trata-se de um real que ele não pode negar e com o qual ele deve e quer trabalhar. Eis porque ele deseja que os alunos se sintam bem com ele. Para ele é importante louvá-los e estimulá-los. Não se trata de excluir aqueles que são menos esportistas. Trata-se, portanto, de estabelecer uma comunidade (registro do imaginário) sem fazer pressão. Aliás, como ele viveu em sua família, onde ele nem foi criticado quando ele fracassou no segundo grau.

Ele fracassou em sua monografia, porque, segundo ele, seu discurso autossócio-construtivista ligado a seu desejo de inovar, de progredir, não era conveniente à banca. Seu fantasma de progresso não permitia que ele pensasse que a banca tivesse outros critérios, mais conservadores. De sua parte houve uma 
transferência, um excesso de confiança, algo de não querer saber por si mesmo, no formador enquanto suposto apoio. Seu fracasso inesperado desestabilizou-o intensamente e levou-o a tentar compreender, e, portanto, fazer borda desse real pelo simbólico. O trabalho sobre o fracasso de sua defesa e, sobretudo, sobre o tom desrespeitoso dos membros da banca trazem a ele um novo significante, o do "fair-play" como atitude sublimatória de lidar com o pulsional.

Há, portanto, professores que também partem de seu(s) significante(s) mestre(s) sobre a relação com o saber, mas de tal modo que eles permitem a seus alunos inscrever-se enquanto sujeitos nesse discurso. Eles organizam o laço social de tal modo que as necessidades, as demandas e resistências dos alunos sejam levadas em conta.

\section{François}

Em sua infância, François não tinha ninguém que se interessasse por ele: "no fundo eles nunca se interessaram por mim; eles não tinham um olhar para mim". O "olhar" do outro lhe faltava. E ele afirma com um ar de desdém: "Meu pai foi carteiro, isso (os estudos, a aprendizagem) não o interessava." Podemos assim nos perguntar se não nos encontramos face a uma injunção de não aprender. Um discurso ou um desejo de saber parece não ter sido transmitido. Só seu "irmão disléxico aproveitava do suporte da mãe para fazer seus deveres".

Para ele "o saber e o aprendizado são dois universos diferentes"...

As coisas que quero realmente saber, interiorizo-as sem pensar muito, e são as coisas que eu guardo. Se estudo algo que... nunca conseguia memorizar (ri). Mesmo hoje sou incapaz de aprender, leio tudo. De fato, sempre tento interiorizar a matéria, do mesmo modo que interiorizava os outros conhecimentos, mas não consigo muito... O eixo era o enchimento de crânio, sobre o aprendizado de cor.... Se você não soubesse a resposta correta você era punido (ri).

Tornar-se professor não era sua primeira escolha. Ele trabalhou em muitas áreas e em todos os níveis do domínio dos cuidados. Para ele, ele era "muito social" como diretor de uma grande empresa. Ele foi despedido. Ele precisava de um emprego para ganhar a vida: "Acumulei muita experiência. E pensei que o ensino seria interessante; acumulei experiências durante vinte anos, agora posso passar para o ensino durante vinte anos e partilhar minhas experiências". Essa transferência de saber poderia, por exemplo, "servir para que menos enfermeiros tenham burnout". 
Esse estagiário quer transmitir aos alunos suas próprias experiências acumuladas durante anos, partir de exemplos para que eles aprendam intuitivamente. Então, ele tem uma imagem do que ele quer ser como professor. É, portanto, com suas representações, fantasmas e afetos que ele quer, e manifestamente sabe transmitir com piadas muito sutis e assim por sedução. Mas seus colegas não gostam dessa abordagem. Para ele, é importante despertar o interesse de seus alunos. Ele não quer transmitir apenas "puro saber". Ele quer que os alunos compreendam as relações entre os elementos; "por que algo é como é e por que esse mundo funciona como funciona?" O saber decorativo, "os fatos, o factual" não são "importantes". Ele tem resistência a isso. O factual e o "fa-tor" 6 parecem ligados em uma mesma cadeia significante que significaria que um fato, um ato, deveria ser recalcado ou negado.

Inscrever-se no discurso didático para ele é um problema. Ele não se sente mais livre, mas preso. "Antes, eu era muito mais despreocupado em minha abordagem, mas tudo se tornou repentinamente terrivelmente sério, com objetivos de aprendizagem e nem sei mais o que... Nunca fiz introdução nem sintese no fim, mas tudo isso era natural, quase funcionou sozinho [...]. O fato de ter menos margem de manobra e de tentar colocar tudo o que é comunicado sob um mesmo chapéu me limitou muito; eu tinha menos naturalidade e também observei que meus cursos se tornavam menos fluidos, menos... Além disso, meu entusiasmo sofreu um golpe, bem como o entusiasmo dos alunos, que eram aliás o perfeito reflexo do meu".

E ele explicita: "Sim. Tudo estava em queda livre [...]. Antes disso, eu improvisava, tinha facilidade. Não tinha nenhum problema em estar diante de uma classe. Mas nunca pensava sobre meu modo de ensinar [...]) E depois aprendi todas essas novas coisas e de um momento para o outro comecei a repensar meu estilo, a me dizer: "Não, não deve fazer desse jeito". Comecei a ter cada vez mais dúvidas. O declínio continuou até que eu atingisse um certo limite".

Confrontado à interpelação do tutor e dos formadores, ele não sabe transformar seu estilo. Sua relação com o saber e com o não saber que não se moviam, não permitiram que ele trabalhasse seu sintoma, isto é, o porquê de não conseguir pensar, estruturar e organizar seu curso. O estagiário finalmente abandonou a formação.

Diante do saber como terceiro e do discurso didático, ele fica inseguro: "Sua autoestima está fragilizada". Sua abordagem, muito baseada sobre o reconhecimento recíproco com os alunos, não bastava para ser bem-sucedido. Não seria um sinal de que o sentido da aprendizagem e do saber não foram transmitidos porque o desejo do pai falhava nesse sujeito?

6 Em francês a palavra facteur significa "carteiro" e "fator". 
Para ele, a própria vivência da escola tem um papel aí. Essa vivência foi, sobretudo, trágica. Ele gostava mesmo das palhaçadas em grupo com seus pares, e sofreu as consequências disso. Eis porque ele sempre odiou a escola. Ora, trabalhar em um lugar antes odiado explica-se como pulsão de repetição em busca de uma nova relação com a escola. Seria um sinal de falta do pai que não cuidava dele e não transmitia o desejo de saber que implica a aceitação do Outro, da falta, da frustração, do risco e do trabalho. Essa dor de pai deixa-o sozinho com suas pulsões que pedem para transcender-se no desejo, assim como uma postura ética. Isso fazia sintoma antes dirigido ao colégio e mais tarde à formação pedagógica. Houve resistência, um “não poder querer" (LACAN, 2013, p. 329) aceitar certos aspectos simbólicos do ofício de professor para ver-se levado por um desejo singular, o melhor escudo contra uma posição depressiva.

Seria preciso trabalhar tal vivência traumática para poder abandonar sua transferência de ódio sobre esse lugar e aí sobreviver. O significante "fator" [facteur] era configurado para ele como "factual" (saber declarativo) e falta de autorização de um desejo de aprender, portanto, "pegar saber" e trabalhá-lo, estruturá-lo. Ele não pôde trabalhar suficientemente esse saber inconsciente e aproveitar disso em tempo útil. Podemos nos perguntar também se o estagiário não estava em uma posição de "Sei, mas ainda assim" como Mannoni (1996, p. 9) formulou. Depois de abandonar a formação pedagógica ele encontra um outro ofício do impossível: o do auxílio social, mais próximo daquilo que seu pai, que ajudava as viúvas necessitadas, transmitiu a ele: "o social”, o convivial.

Como François, alguns professores tentavam transferir seu modo de ensinar aos alunos, supondo que todos podiam lidar com isso. Os conteúdos transmitidos referem-se menos a um saber terceiro do que a seu ponto de vista ou à sua experiência com um sujeito.

\section{Nathalie}

Nathalie é estagiária de biologia. Depois de trabalhar em outros domínios, ela segue o percurso da formação pedagógica. Nathalie vem de "uma família camponesa e passava muito tempo na fazenda de seus avós." Para essa estagiária de ciências naturais, o significante "vida" se repete, articulado ao significante "útil". "Era preciso que eu tivesse uma formação profissional, mas isso seria do tipo aprendizagem já que eu não ficava sem fazer nada e também não estragava minha vida".

O mesmo significante "vida" surge quando ela escolhe seus estudos universitários em biologia. Ela não continua em letras porque ela havia "gostado disso", mas não via a si mesma "continuando a escrever dissertações". Ela estava "cansada da literatura". 
"Penso que se tratava mais de um interesse pelo próprio saber, pela... para realmente aumentar meu conhecimento nessa matéria, nessa disciplina. ... Sim, era mais isso, como funciona a vida, como funcionam as florezinhas, as plantinhas, os animais e como funciona o corpo humano? Realmente era mais isso".

Ainda assim ela não se sentia feliz com essa escolha, ela se dizia "ingênua", pois ele não oferece saídas suficientes, um significante em que esconde

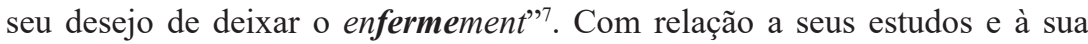
formação pedagógica os significantes vidas e útil ressurgem. Enquanto sujeito ela parece situar-se entre os dois: "ainda assim seria preciso um pouco de ... instrumentos práticos? Bah, é uma decepção. Ehm. É um luto. Penso que não temos escolha, é preciso fazê-lo e ehm, sim, idealmente sim, seria preciso ter mais instrumentos práticos. ... se eu dedico dois anos da minha vida para isso, é para que eu saia mais instruida do que quando entrei".

Todos se encontram em situações em que têm dificuldade em mudar uma atitude e em se dar conta do fantasma que o sustenta. Vejamos nesse sentido as propostas da professora em questão, que tentava ser excessivamente gentil com seus alunos.

"Portanto hum, portanto hum, agora eu parto muito mais armada. Penso que se tratava realmente desse aspecto de gestão da classe... Porque senão eu teria continuado a fazer... [...] a fazer erros"... Em ser excessivamente gentil, a não fazer o enquadre. E não, a ter escrúpulos, a... hum, tipicamente a ter escrúpulos em relação à autoridade e tudo isso, por medo de ser autoritária... então ser muito gentil e permitir que passem por cima de mim e ser engolida pelos alunos e hum, é isso, mas agora eu sei como refazer".

Foi a prova, a experiência do real, aqui de um conflito pulsional que fez com que ela pensasse e pedisse ajuda a seu tutor para aprender a lidar com isso. O confronto com a própria verdade, no caso o medo diante do lado agressivo daquele que está em posição de autoridade, e, portanto, de sua própria violência ou ódio, permite uma mudança de atitude. Houve uma formação no sentido de uma transformação no nível das pulsões. Graças ao reconhecimento desse conflito que se expressava igualmente por meio dos significantes autoridade $\mathrm{e}$ autoritário ela soube transformar, sublimar suas pulsões agressivas em estratégias para disciplinar e seduzir. Depois disso ela se diz muito mais armada.

Eis um exemplo de contato com sua própria verdade. Com efeito, Lacan (Seminário "O ato psicanalítico" aula de 19 de junho de 1968, inédito) formula assim: "A verdade jaz no ponto em que o sujeito recusa saber. Tudo o que é rejeitado pelo simbólico reaparece no real. Tal é a chave do que chamamos o

7 [Fechamento]. O autor ressaltou ferme nessa palavra, que significa fazenda. 
sintoma. O sintoma é o nó real onde se encontra a verdade do sujeito". Nesse caso, a estagiária trabalhou o saber inconsciente incluído no sintoma em questão. Porque ele não foi reconhecido inicialmente como saber, ele foi rejeitado do simbólico. E ressurgiu no real, como diz Lacan.

Desse modo ela tem a experiência de que transmitir também é uma questão de poder. Com efeito, a transmissão do saber comporta uma função conservadora da cultura e dos discursos ambientes para que a sociedade continue. "Deriva daí o domínio de uma geração sobre outra". (BAÏETTO, 1982, p. 47). O saber faz força de lei no campo escolar. E, pelo fato de ter a função de transmitir esse saber, o professor tem uma função com o poder simbólico que difere, portanto, do registro de toda potência imaginária ou de estratégias de sedução.

O tema de vida, e também de morte e da agressividade voltavam regularmente em seu discurso. O medo de ser "muito jovem" e depois "muito velha" em relação aos alunos, de ser engolida ou de fazer mal, incomodavam-na. Mas ela soube trabalhar esse aspecto do saber lidar com a pulsão de destruição assim como sublimar a pulsão agressiva. Em seguida essa estagiária mantém o percurso e tenta transmitir a lei simbólica em relação à vida em sociedade e ao trabalho escolar. Para isso, ela não teme mais assumir uma posição de autoridade: “É meu objetivo, é o de ser um pouco um cão pastor alemão. ... Empurrar aqui, roer ali". Ela quer transmitir "um saber útil, para poder fazer escolhas responsáveis". Mas esse significante de utilidade finalmente é articulado à literatura. Ela pode viver seu desejo pela literatura ensinando mais línguas do que ciências naturais.

Houve uma formação no sentido em que ela aprendeu a trabalhar seu fantasma de mordidas em relação ao grupo classe e a ensinar o que a levava a ver com mais clareza o aspecto de saber do terceiro e sua responsabilidade de professora.

\section{Carla}

Essa jovem professora foi nomeada professora de geografia. Ela participa de diferentes projetos fora da escola. Carla nos fala intensamente de situações em que seus pais tentaram influenciar sua relação com o saber, "A transmissão de saber nunca foi irritante. Ela estava presente de modo subjacente. Ela fez parte de sua (filhos e pais) vida... bem, ok, se eu dissesse que não queria ler o livro, então eu não era forçada a lê-lo, mas era melhor ler, já que as escolhas eram limitadas; ler um livro era melhor do que olhar para o céu".

Não surpreende que um termo apareça várias vezes: é a "ba-gagem" que ela recebeu de seus pais. Trata-se aqui de um significante, polissêmico, portanto, que também orienta seu discurso em relação a seus alunos. 
Ela fala aqui do crescimento pulsional em busca de satisfação, confrontado ao trabalho educativo de seus pais, e, portanto, a transmissão da ordem simbólica, como Freud explicitou em seu mal-estar na cultura. Ele descreveu os efeitos sintomáticos, bem como os limites desse trabalho de civilização. E Carla fala de que modo ela se deixa levar para ter prazer, sob o risco de transgredir as regras ou a entrar em conflito com formadores. Ela diz que esses últimos a inspiram: "Sempre estive em oposição, e ainda estou". É com um prazer visível que ela fala do fato de não ter realmente seguido o aconselhamento parental na escolha de estudos universitários "que sirvam para algo" e "ter escolhido a geografia ainda que não existam muitos cargos a ocupar". O significante ba-gagem ${ }^{8} \mathrm{se}$ articula ao significante: "en-gage-ment" [en-gage-amento]. Entre outros, foi com esse significante encontrado em um movimento de jovens que ela tomou uma certa distância do discurso "pesado" de seus pais. "Formar-se, para ela, significa mudar o mundo".

O significante 'engageamento' muitas vezes articulado ao de bagagem influencia seus estudos, seu interesse pelos países em vias de desenvolvimento, bem como seus objetivos de professor-estagiário: "Ser professor constitui um interlúdio entre a transmissão de saber e a transmissão do saber-viver e saber-ser".

Como professora, ela ainda se encontra dividida enquanto sujeito, entre esses dois significantes equívocos, bagagem e 'engageamento', entre liberdade e dívida ou 'gage'. Para ela, a geografia é "fazer um pouco de turismo nas classes inferiores ... estimular a curiosidade deles para olhar para fora." Nas classes superiores "trata-se de focalizar o desenvolvimento, abordar um pouco os temas sociocráticos como o desenvolvimento, a fome, a água, e tudo que aí está em jogo". A geografia física a interessa menos, ainda que ela tenha menos resistência do que antes para ensiná-la. Antes de tudo, seu interesse é pela geografia humana. Seu objetivo é a transmissão de cultura geral e ela escolhe temas que possam interessar aos jovens: "trata-se unicamente de interesse ... os resultados (notas) não são importantes (para eles)". Para ela, permanecerão mais importantes a "transmissão de valores" e o "nível social" no que se refere a seu trabalho na classe. Ela considera o saber em uma abordagem ética e profilática. Ela quer "abrir os olhos deles em relação ao engano".

Assim, ela se encontra mais do lado educativo que, segundo Charles Melman (1993, p. 4), consiste essencialmente em dar à criança um modo de relação, "um acesso ao desejo de um modo que lhe permita assumir não apenas seu sexo, mas também seus ideais, e que também lhe dê essa energia que poderá

8 Gage, em francês, é empenho, penhor. 
ser-lhe necessária na vida. A educação lhe dá também uma certa coragem, um certo otimismo, uma certa vontade".

Desde as primeiras palavras, por ocasião da primeira entrevista, ela fala de "seus outros projetos políticos e associativos a desenvolver (durante) sua vida".

Conflitos transferenciais com uma tutora, uma formadora e o dispositivo são a expressão disso. Hesitando em assinar seu primeiro contrato, com o compromisso de cinco anos em um liceu, ela afirma: "Tive um pouco [...] de algum modo, porque pensei, agora é definitivo, cinco anos em um cargo, agora você se tornou adulta, agora você chegou à vida, não se irrite, e o que você queria, e.... sim". Presa entre bagagem e "engageamento" ela sente seu "gage" [empenho], sua dívida a pagar pela bagagem recebida, mas que se paga "engageando"-se para a geração seguinte. Por esse "engageamento" ético, bem como com sua própria transgressão das regras em seu percurso de formação, ela parece reviver os determinantes de se tornar adulta, de se separar ligando-se à lei simbólica, e, portanto, trabalhar com o gozo e a transgressão.

Aliás, também é ao longo de uma outra cadeia significante que Carla expressa seu desejo de afastar-se e sua necessidade de criticar seu meio familiar e social. O sofrimento é consequência disso porque ela fica dividida entre seus estudos longe de casa ou em uma cidade próxima. Nesse caso a formação não conduziu a grandes transformações no nível da relação com o saber. O desejo de transmitir conhecimento permanecia em segundo plano em benefício do desejo de educar.

\section{Os sintomas que levam a transformações da relação com o saber}

Pudemos constatar que os diversos atores se encontravam confrontados a disfunções ligadas à sua história e à sua singularidade. Freud (1991, p. 521) afirma: "Tudo o que perturba a continuação do trabalho é uma resistência". Nesse sentido, constatamos que também se tratava de problemáticas que mostravam que a aprendizagem de gestos profissionais estava ligada, nesse caso, a um esforço necessário de subjetivação do ofício e mais especialmente para dar-se conta da relação com o saber subjetivo singular e daí obter as consequências no enquadre do dispositivo de formação ou do enquadre institucional.

Esse trabalho de subjetivação ao longo da formação levou-os, portanto, a uma outra relação com eles mesmo enquanto eu, a seu inconsciente saber não sabido, às múltiplas pulsões ligadas ao saber, aos fantasmas que orientavam seu modo de se relacionar com o saber científico e outro, às teorias didáticas e peda- 
gógicas. Eles se davam conta das transferências operadas sobre sujeitos supostos saber e sobre locais institucionais como a escola e a universidade, bem como de suas questões éticas em relação ao saber. Eles acabaram por instalar uma outra relação com seu sintoma questionando-o em relação ao saber que ele contém.

Pudemos detectar que se tratava em parte de problemas que se repetiam. Para Hélène, por exemplo, vê-se bem que ela repete estratégias até o "crash". É assim que ela vive, sofrendo com seu fantasma de perfeição, seu desejo de ser bem-sucedida. De uma posição passiva e autodestrutiva ela passa para uma posição ativa. Sobre isso Lacan (1986, p. 251) afirma, a respeito da pulsão de morte ligada à repetição: há "Vontade de destruição. Vontade de recomeçar... Vontade de criação a partir do nada, vontade de recomeço".

Se a maior parte dos estagiários foi aprovada na formação, é porque eles puderam articular novos significantes/saber ou sob outros olhares com o saber da cadeia significante consciente e inconsciente existente. Para a maioria, essas transformações de sua relação consigo mesmo, bem como no nível da relação com o saber acabaram por influenciar igualmente a relação com o saber que eles querem transmitir.

\section{A relação com o saber, o estilo do sujeito professor e as condições de possibilidade de uma transformação dessa relação}

Finalmente coloca-se a questão do que se pode dizer a partir das entrevistas sobre a relação com o saber e as condições de seu desenvolvimento junto ao professor.

\section{A relação do professor com o saber}

$\mathrm{O}$ ato de ensinar consiste em levar o aluno de um saber adquirido e de um não saber para novos saberes. O professor - de modo consciente ou não - acompanha o aluno como sujeito e, portanto, também como ser de desejo, de "falaser", e o sustenta na articulação de seu saber inconsciente para o saber "sabente". Se necessário, ele deve considerar-se responsável por transmitir ainda a lei simbólica para que o aluno aprenda a inscrever-se na lei do impossível, isto é, a satisfação é impossível. Tudo isso não deixa de ter efeito sobre seu corpo de professor, portanto, em seu próprio inconsciente.

Assim, transmitir saber coloca continuamente ao professor (estagiário) a questão de sua relação com o saber e com o saber não-sabido. A partir de nossa 
pesquisa podemos afirmar que é importante para o professor questionar-se sobre seu desejo de saber e sobre os objetos desse desejo. Qual é minha relação inconsciente com o objeto de desejo/libidinal que constitui o saber disciplinar codificado e que provoca identidade e segurança ou incerteza/angústia? Para isso é preciso que ele se dê conta do que toca o fantasma e as pulsões que subentendem sua relação. De que modo ele utiliza, por exemplo, o saber, em sua relação com os alunos: como objeto narcísico, de defesa ou de partilha? Como toda aprendizagem, formar-se no ofício de professor demanda aceitar uma perda de gozo, aceitar uma castração simbólica. Nesse sentido, é importante que o professor-estagiário saiba estar aberto tanto ao saber quanto à falta dos alunos e saiba trabalhar com isso. Enquanto sujeito (suposto) 'sabente' e suposto saber, ele ocupa uma posição de poder. Eis porque ele também deve dar-se conta do lado pulsional e fantasmático que podem conduzi-lo a atos de avaliação e outros, na contramão de uma ética profissional.

\section{Condições de possibilidades de transformação da relação com o saber durante o percurso de formação}

A partir de nossas análises das entrevistas, podemos dizer que transformações no nível do saber e em seguida no nível do ato de ensinar podem se estabelecer se o professor-estagiário estiver aberto ao saber não sabido encerrado em disfunções e sintomas que ele produz.

Para que o novato possa se sair bem, é preciso que ele tenha um formador de campo que não se veja unicamente como responsável por sustentar a aprendizagem de gestos profissionais "abstraídos" do corpo e do inconsciente do candidato, mas que ele possa ajudá-lo, se necessário, a questionar a relação com o saber e, portanto, igualmente, a relação consigo mesmo enquanto sujeito inconsciente e com a verdade pulsional. (LACADÉ, 2013, p. 70). É preciso que alguém o ajude a ter acesso às suas crenças sobre a transmissão de saber e a colocar isso em palavras.

Apoiando-se em sintomas que emergiram dos estagiários, o formador deve ajudar a desenvolver novos saberes ou posicionamentos, o que implica assumir também uma perda de gozo. Isso é possível no caso em que ele não tente unicamente criticar as disfunções dos estagiários, mas ouvindo-os para detectar o saber e o sofrimento que ali se encerra, tentando transformá-lo em motor de criatividade, convertê-lo em ato, em ato de desejo: "potencialidade subjetiva, potência de existir, alegria, gozo”. (LIPPI, 2013, p. 268). 


\section{Conclusão}

Detectamos que a relação com o saber se instalou muito cedo na vida dos estagiários e foi influenciada pelos discursos e desejos parentais e institucionais. A maior parte pode iniciar um processo de subjetivação relacionado a esses discursos e desejos.

É principalmente a abertura ao saber não sabido que faz com que os estagiários avancem. O modo como eles posicionam o aluno enquanto sujeito de desejo ou de horror do saber faz descobrir sua relação com a transmissão de saber.

O conceito da relação com o saber parece-nos mostrar suficientemente sua pertinência heurística. Depois desse trabalho, realizamos, com dois projetos distintos, uma análise sobre a relação com o saber de jovens "desistentes escolares" que retomaram seus estudos e de seus professores.

\section{REFERÊNCIAS}

BAÏETTO, M.-C. Le désir d'enseigner. Paris: ESF, 1982.

BEILLEROT J.; BLANCHARD-LAVILLE, C.; MOSCONI, N. (Dir.). Pour une clinique du rapport au savoir. Paris: L'Harmattan, 1996.

BLANCHARD-LAVILLE, C. Au risque d'enseigner. Paris: Puf, 2013.

BLONDEAU, S. Recherche thématique clinique et objet complexe. In: DOUVILLE, O. (Dir.). Les méthodes cliniques en psychologie. Paris: Dunod, 2006. p. 25-42.

BROUSSEAU, G. Fondements et méthodes de la didactique des mathématiques. Recherche en didactique des mathématiques, n. 7/2, p. 33-115, 1986.

CHARLOT, B. Du rapport au savoir: éléments pour une théorie. Paris: Anthropos, 1997.

CHAUMON, F. La loi, le sujet et la jouissance. Paris: Editions Michalon, 2004.

FLICK, U. Das episodische Interview. In: OELERICH, G./O., H.-U. (Hrsg.). Empirische Forschung und Soziale Arbeit. Ein Studienbuch. Wiesbaden: VS Verlag für Sozialwissenschaften, 2011. p. 273-280.

FREUD, S. (1900). Die Traumdeutung. GW II-III. Frankfurt am Main: Fischer, 1991.

FREUD, S. (1905). Drei Abhandlungen zur Sexualtheorie. Frankfurt am Main: Fischer, (1991). 
FREUD, S. (1908). Über infantile Sexualtheorien. GW VII. Frankfurt am Main: Fischer, (1999).

FREUD, S. (1930). Malaise dans la civilisation. Paris: PUF, (1995).

FREUD, S. (1937a). Konstruktionen in der Analyse. GW XVI. Frankfurt am Main: Fischer, (1999).

FREUD, S. (1937b). Die endliche und die unendliche Analyse. GW XVI. Frankfurt am Main: Fischer, (1999).

FREUD, S. (1938). Abriss der Psychoanalyse. GW XVII. Frankfurt am Main: Fischer, (1999).

HATCHUEL, F. Savoir, apprendre, transmettre. Une approche psychanalytique du rapport au savoir. Paris: L'Harmattan, 2005.

LACADE, P. La vraie vie à l'école. La psychanalyse à la rencontre des professeurs et de l'école. Paris: Editions Michèle, 2013.

LACAN, J. Ecrits. Paris: Editions du Seuil, 1966.

LACAN, J. Le Séminaire, livre XI, Les quatre concepts fondamentaux de la psychanalyse, 1963-1964. Paris: Edition du Seuil, 1973.

LACAN, J. Le séminaire livre XX, Encore, 1972-1973. Paris: Du Seuil, 1975.

LACAN, J. Séminaire, livre XV, L'acte psychanalytique, séance du 19 juin 1968, inédit, 1989.

LACAN, J. Le Séminaire, livre VII, L’éthique de la psychanalyse, 1959-1960. Paris: Du Seuil, 1986.

LACAN, J. Le Séminaire livre XVII, L'envers de la psychanalyse, 1969-1970. Paris: Editions du Seuil, 1991.

LACAN, J. Autres écrits. Paris: Edition du Seuil, 2001.

LACAN, J. Je parle aux murs. Paris: Editions du Seuil, 2011.

LACAN, J. Le Séminaire Livre VI, Le Désir et son interprétation. Paris: Du Seuil, 2013.

LIPPI, S. La décision du désir. Toulouse: Eres, 2013.

MANNONI, O. Clefs pour l'imaginaire ou l'Autre scène. Paris: Du Seuil, 1996.

MELMAN, C. Qu'est-ce qu'éduquer un enfant? In: Le Bulletin Freudien no 20, 1993. Disponível em: <http.//www.association-freudienne.be/fr/publications/>.

MENES, M. L'enfant et le savoir. D'où vient le désir d'apprendre? Paris: Editions du Seuil, 2012.

ROCHEX, J.-Y. Rochex Jean-Yves, "La notion de rapport au savoir: convergences et débats théoriques”. Pratiquespsychologiques, n. 10, p. 93-106, 2004. 
SAURET, M.-J. Psychanalyse et politique. Huit questions de la psychanalyse au politique. Toulouse: Presses Universitaires du Mirail, 2005.

SAURET, M.-J.; DOUVILLE, O. A propos de la démarche clinique et de son rapport au singulier. In: DOUVILLE, O (Dir.). Les méthodes cliniques en psychologie. Paris: Dunod, 2006. p. 3-24.

SAURET, M.-J. L'effet révolutionnaire du symptôme. Ramonville Saint-Agne: Erès, 2008.

TERRISSE , A. Rapport au savoir et enjeux de savoir pour des enseignants d'EPS: “Une médiation aisée pour situer le sujet: d'un rapport au savoir". Actualité de la Recherche en Education et en Formation, Strasbourg, 2007.

Texto recebido em 17 de dezembro de 2016.

Texto aprovado em 03 de janeiro de 2017. 
